\title{
Biodegradação de compostos fenólicos presentes em águas residuárias da indústria metalúrgica
}

\author{
Biodegradation of phenolic compounds present in the wastewater of the \\ metallurgical industry
}

\author{
Sideney Becker Onofre $\left.{ }^{1}{ }^{*}\right)$ \\ Amarildo Antonio Tessaro ${ }^{2}$ \\ Douglas Refosco ${ }^{3}$ \\ Dirceu Abatti ${ }^{4}$
}

\section{Resumo}

O presente trabalho objetivou selecionar fungos filamentosos resistentes a condições adversas, isoladas de águas residuárias de lagoas de tratamento de uma indústria metalúrgica, capazes de degradar compostos fenólicos. Foram isolados e purificados quatro fungos filamentosos dessas águas residuárias, que são: Aspergillus flavus (I$\left.{ }_{4}\right)$, Cladosporium sp. (I- $\left.{ }_{6}\right)$, Penicilium sp. (I- $\left.{ }_{10}\right)$ e Phoma sp. $\left(\mathrm{I}_{-13}\right)$. Dentre as espécies fúngicas isoladas foi observado que elas pertencem ao grupo de fungos filamentosos de pigmentação escura. Devido ao complexo melanínico em suas paredes celulares, estes são chamados de dematiáceos ou fungos negros, os quais comumente apresentam melanina formada pelo polímero 1,8-dihidroxinaftaleno (DNH), produzido no citoplasma e excretado na parede celular. Os níveis de degradação dos compostos fenólicos, expressos em mg de equivalente de ácido gálico, foram diferentes para cada um dos fungos avaliados, sendo que a maior degradação ocorreu nos tempos de 24 e 48 horas de crescimento. Verificou-se que a linhagem $\mathrm{I}^{-}$de Penicilium sp. foi a que apresentou os melhores resultados, degradando $478 \mathrm{mg}$ em 48 horas, tendo, também, produzido os maiores índices de biomassa fúngica. $\mathrm{O}$ mesmo comportamento foi verificado com o consumo da glicose na qual a linhagem $\mathrm{I}_{6}$ de Cladosporium sp. consumiu glicose fornecida.

Palavras chave: Biorremediação, compostos fenólicos, fungos filamentosos.

1 Dr.; Processos Biotecnológicos; Universidade Federal do Paraná, UFPR, Brasil; Professor titular da União de Ensino do Sudoeste do Paraná - UNISEP - Campus de Dois Vizinhos e Francisco Beltrão; Endereço: Av. União da Vitória, 14, Bairro Minuguaçu, Francisco Beltrão - Paraná; E-mail: beckerside@unochapeco.edu.br

2 Me.; Desenvolvimento de Tecnologia; Institutos Lactec, LACTEC, Brasil; Professor na União de Ensino do Sudoeste do Paraná (UNISEP); Endereço: Av. União da Vitória, 14, Bairro Minuguaçu, Francisco Beltrão - Paraná; E-mail: amarildo@unisep.edu.br

3 Me.; Desenvolvimento de Tecnologia; Institutos Lactec, LACTEC, Brasil; Atualmente é Doutorando em Engenharia Mecânica pela PUC-PR e Engenheiro Civil do Conselho Regional de Engenharia, Arquitetura e Agronomia do Estado do Paraná; Endereço: União de Ensino do Sudoeste do Paraná, Campus Dois Vizinhos. Av. Presidente Kennedy, 828, Nossa Senhora Aparecida. CEP: 85660000 - Dois Vizinhos, PR - Brasil; E-mail: douglasrefosco@gmail.com

4 Me.; Química; Fundação Universidade Regional de Blumenau, FURB, Brasil; Secretario de Viação e Obras do Município de Francisco Beltrão; Endereço: R. Octaviano Teixeira dos Santos, 1000 - Centro, Francisco Beltrão - PR, CEP: 85601030; E-mail: dirceuzanardi@hotmail.com

\begin{tabular}{llllll}
\hline Ambiência & Guarapuava (PR) & v.14n.3 & p.539-548 & Set/Dez 2018 & ISSN $1808-0251$
\end{tabular}




\section{Abstract}

This study sought to select filamentous fungi resistant to adverse conditions, isolated from the wastewater of metallurgical treatment ponds, capable of degrading phenolic compounds. Four filamentous fungi were isolated and purified from these wastewaters: Aspergillus flavus (I-4), Cladosporium sp. (I-6), Penicillium sp. (I-10) and Phoma sp.(I-13). It was observed that the isolated fungal species belonged to the group of filamentous fungi with dark pigmentation. Because of the melamine complex in their cell walls, these fungi are called black or Dematiaceous fungi, which commonly have the melanin polymer formed by 1,8-dihydroxynaphthalene (DNH) produced in the cytoplasm and secreted in the cell wall. The degradation levels of the phenolic compounds, expressed in $\mathrm{mg}$ of gallic acid equivalents, were different for each tested fungi, with the largest degradation occurring at 24 and 48 hours of growth. The strain I-10 of Penicillium sp. Was found to have the best results, degradating $478 \mathrm{mg}$ in 48 hours, and also producing the highest rates of fungal biomass. The same behavior was observed with glucose uptake where the I-6 strain of Cladosporium sp. consumed the provided glucose.

Keywords: Bioremediation, phenolic compounds, filamentous fungi.

\section{Introdução}

As contaminações das águas, o aumento das atividades industriais, juntamente com os resíduos introduzidos no ambiente estão cada vez mais degradando os ecossistemas naturais e os recursos disponíveis para o homem, e muitas dessas substâncias são de natureza persistente, como exemplo, os compostos fenólicos.

Os compostos fenólicos apresentam grande toxidade e são dificilmente degradados ou reciclados, ocasionando graves problemas para a biota local e para a saúde humana. No caso das águas residuárias, dificulta o processo de tratamento biológico, suscitando em dúvidas devido à possível contaminação das águas que abastecem a população (CUNHA, 1996, CHENGA et al., 2012).

Os fenóis estão presente, nas mais diferentes concentrações, em diversos tipos de águas residuárias, industriais, farmacêuticas e têxteis, de resinas e de papel, em efluentes de fundições de metais e refinarias de petróleo, bem como em águas regionais, como as residuárias de oficinas mecânicas e postos de gasolina, onde ocorre despejo de poluentes tóxicos ao meio ambiente (COLL, 1993, XU; YANG, 2014).

Os fenóis e seus derivados contaminam os solos e, conseqüentemente, lençóis freáticos adjacentes a esses empreendimentos, onde a utilização de matérias-primas que têm em sua composição é uma constante. Uma vez na água ou no solo, os compostos fenólicos são facilmente lixiviados, contaminando os lençóis freáticos. Quando encontrados em elevadas concentrações podem representar perigo para os consumidores da água contaminada (BENNET, 1998).

As propriedades biológicas dos compostos fenólicos estão relacionadas com a atividade antioxidante que cada fenol exerce sobre determinado meio. A atividade dos antioxidantes, por sua vez, depende da estrutura química, podendo ser determinada pela ação da molécula como agente redutor (BUMPUS et al., 1985, DAÍ et al., 2015). 
A concentração de $0,5 \mathrm{mg} / \mathrm{L}$ de fenóis foi estabelecida como padrão de lançamento para qualquer tipo de efluente, de acordo com a resolução do Conama, sendo que, no Brasil, em águas destinadas ao abastecimento, o Ministério da Saúde determinou que o limite máximo permitido de fenol em água destinada ao abastecimento público é de $0,1 \mathrm{mg} / \mathrm{L}$, a fim de evitar danos à saúde humana. Em uma portaria mais recente do Ministério da Saúde, Portaria no 518 (BRASIL, 2004), é estipulada, em águas de abastecimento, concentrações máximas apenas para compostos derivados do fenol, tais como pentaclorafenol $(9 \mathrm{mg} / \mathrm{L})$ e 2,4,6-triclorofenol $(0,2 \mathrm{mg} / \mathrm{L})$.

Com a necessidade de preservar os recursos naturais, o homem busca com as tecnologias, minimizar os impactos causados pela presença desses compostos no meio. Diante disso, o uso de fungos em reatores visando o tratamento dos mais diferentes tipos de águas residuárias vem crescendo e despontando como uma nova tecnologia de biotratamento. Os trabalhos nessa área são poucos, os dados são bastante promissores quanto à utilização desses microorganismos na biorremediação de efluentes, incluindo os que possuem, em sua composição, substâncias como fenóis (VASSILEV et al., 1994, NAZARI; KASHANIAN; RAFIPOUR, 2015).

O metabolismo microbiano de compostos aromáticos tem sido muito estudado. A maior parte do conhecimento sobre rotas metabólicas da degradação desses compostos encontrase fundamentada em bactérias. No entanto, estudos têm mostrado que fungos atuam como decompositores de compostos aromáticos, entre esses os fenóis (SANTOS; LINARD, 2004).

A potencialidade de se empregar fungos para o tratamento de substâncias persistentes está relacionada à produção de enzimas extracelulares, cujas ações tornam os organopoluentes mais acessíveis a biodegradação. Além disso, os fungos são organismos capazes de suportar mudanças bruscas na concentração de matéria orgânica, de tolerar grandes variações no $\mathrm{pH}$ e de a temperatura se adequar a variações, além de suportar a escassez de umidade e de oxigênio, dando viabilidade ao trabalho (SEKHAR et al., 1998).

O emprego dos fungos na remoção dos poluentes começou a ser estudado nos últimos trinta anos do século XX. De acordo com Peralta-Zamora et al., (1998), um dos primeiros trabalhos que se tem notícia foi com o uso de Saccharomyces cerevisiae para remoção de lindano e dieldrin por Nobles (1965) seguido do trabalho de Khindaria (1975), que estudou a degradação de heptacloro por fungos do gênero Aspergillus. Contudo, foi nas últimas décadas que houve incremento nas pesquisas de biodegradação por fungos (RODRIGUES, 2006).

Segundo Kunz et al., (2001), Phanerochaete chrysosporium foi uma das primeiras espécies de fungos no início da década de 70, no século XX. Essa espécie apresentou resultados promissores na degradação biológica de compostos persistentes, principalmente devido à produção de enzimas ligninases, peroxidases e manganês peroxidase (ANDER; MAZULLO, 1997; KUNZ et al.,2001, RODRIGUES, 2006).

As fenoloxidases e peroxidases são oxidoredutases, enzimas caracterizadas pela catálise de reações de transferência de elétrons ou átomos de hidrogênio de um composto para outro. Estas representam o maior grupo de enzimas envolvidas com a atividade do metabolismo secundário dos fungos filamentosos, e comumente estão associadas com a síntese de melaninas e outros pigmentos. As fenoloxidases ou polifenoloxidases dividem-se em duas subclasses: lacases e tirosinases (LEATHAM; STAHMANN, 1981; DURAN; ESPOSITO, 2000). Os termos fenoloxidases, fenolases ou polifenoloxidases são utilizados para descrever enzimas que catalisam a oxidação de compostos aromáticos pelo oxigênio molecular reduzindo-o a água (GRIFFITH, 1994; THURSTON, 1994; CHENGA et al., 2012). 
Assim, o presente estudo selecionou fungos filamentosos capazes de degradar compostos fenólicos presentes em águas residuárias da indústria metalúrgica.

\section{Material e Métodos}

Foram coletadas amostras de águas residuárias de uma lagoa de tratamento de águas residuárias de uma indústria metalúrgica localizada no município de Pato Branco, Estado do Paraná, Brasil. Durante a coleta com frascos plásticos, utilizaram-se os procedimentos descritos nas normas NBR 9897/87 e NBR 9898/87, mantendo a proporção entre o líquido e o sólido em suspensão. Posteriormente, as amostras foram armazenadas a uma temperatura de $10{ }^{\circ} \mathrm{C}$.

Cada uma das amostras foi inoculada pelo método de profundidade (pour plate) em meio de cultura BDA em pH 3,5 acidificado com ácido tartárico. Após a inoculação, essas placas contendo o material inoculado foram incubadas a $28 \pm 2^{\circ} \mathrm{C}$ por sete dias.

Após esse período foram realizadas contagens totais das colônias e, posteriormente, realizadas as devidas purificações de cada uma das linhagens caracterizadas durante o crescimento. Essas colônias purificadas foram armazenadas em tubo inclinado contendo meio Sabouraud e armazenado em refrigerador a $-4^{\circ} \mathrm{C}$, para posterior identificação, seleção e avaliação.

A identificação das linhagens foi realizada através de análises das características morfológicas de cada fungo, sendo observada a coloração e a textura superficial da colônia de fungos e as características das hifas, a partir da técnica do microcultivo, seguido de coloração com azul de lactofenol.

O meio de cultura contendo ácido gálico (MAG) foi preparado adicionando-se $15 \mathrm{~g}$ de extrato de malte, $10 \mathrm{~g}$ de glicose, $10 \mathrm{~g}$ de ácido gálico, $20 \mathrm{~g}$ de agar em um litro de água destilada. Devido à provável hidrólise do agar, foi adicionado o ácido em frasco separado, contendo $50 \mathrm{~mL}$ da água destilada utilizada no meio de cultura. $\mathrm{O}$ meio foi esterilizado em autoclave, durante 15 min, a $121^{\circ} \mathrm{C}$ e $1 \mathrm{~atm}$ de pressão (DAVIDSON et al., 1983).

A biomassa fúngica foi quantificada utilizando como substrato o meio MAG, (NOBLES, 1965; DAVIDSON et al., 1983); $\mathrm{pH} 3,5$, isento de ágar, a uma temperatura de $28^{\circ} \pm 2^{\circ} \mathrm{C}$. O crescimento se deu em frascos erlenmeyers com capacidade de $250 \mathrm{~mL}$, em agitador orbital com agitação de $150 \mathrm{rpm}$. A biomassa foi determinada, nos tempos de 24, 48 e 96 horas de crescimento. Essa determinação foi realizada após filtragem do meio em papel filtro previamente pesado. Posteriormente, esse papel filtro com a massa fúngica foi colocado em forno de secagem a 100 ${ }^{\circ} \mathrm{C}$ até a secagem completa e o peso anotado. Procedeu-se o cálculo e o resultado foi dado em peso de Biomassa Seca (BS). Sendo a biomassa fúngica determinado pelo peso final, diminuído o peso do papel filtro.

A quantificação de glicose foi determinada por cromatografia líquida de alta eficiência em equipamento Shimadzu, modelo LC-10AD, com emprego de padronização externa. A análise da glicose foi realizada em coluna m-Bondapak $\mathrm{NH}_{2}$, utilizando água-acetonitrila (15:85) como fase móvel e detector de índice de refração Shimadzu Rid-6A (MACRAE, 1988).

Os teores de fenóis totais das águas residuárias foram determinados por espectrofotometria, utilizando o reagente de Folin-Ciocalteu e Folin-Denis de acordo com a metodologia descrita por Tsimidou et al. (1992) e curva padrão de ácido gálico. Os resultados foram expressos em mg de equivalente de ácido gálico para $1000 \mathrm{~mL}^{-1}$ do meio de cultura (AOAC, 1970). Para isso, foi construída uma curva padrão com o ácido gálico. As leituras foram realizadas em espectrofotômetro a 760nm (FOLIN-DENIS, 1912; FOLIN-CIOCALTEU, 1927; WATERMAN; MOLE, 1994). 
A análise estatística foi realizada com auxílio do programa Statistica, versão 5.0. As análises de variância foram realizadas segundo normas da ANOVA. As diferenças significativas entre as médias foram determinadas pelo Teste de Tukey. Todas as atividades foram realizadas em triplicata.

\section{Resultados e Discussão}

Os resultados obtidos com o isolamento de fungos filamentosos de águas residuárias da indústria metalúrgica, estão apresentados nas Tabelas 1 e 2 .

\section{Tabela 1 - Fungos filamentosos isolados de águas residuárias da indústria metalúrgica.}

\begin{tabular}{ccc}
\hline Microrganismos & $\mathbf{N}^{\mathbf{0}}$ de colônias & Linhagem \\
\hline Aspergillus flavus & 123 & $\mathrm{I}-{ }_{4}$ \\
Cladosporium sp. & 65 & $\mathrm{I}-{ }_{6}$ \\
Penicilium sp. & 49 & $\mathrm{I}^{-}$ \\
Phoma sp. & 12 & $\mathrm{I}^{-}$ \\
\hline
\end{tabular}

Foram isoladas e purificadas 04 (quatro) linhagens de fungos filamentosos de águas residuárias da indústria metalúrgica. As espécies isoladas foram: Aspergillus flavus $\left(\mathrm{I}_{-}{ }_{4}\right)$, Cladosporium sp (I- 6 ), Penicilium sp ( $\left(\mathrm{I}_{10}\right)$ e Phoma sp (I- $\left.{ }_{13}\right)$.

Após o isolamento, as quatro linhagens foram avaliadas quanto a sua capacidade de degradar compostos fenólicos. Os comportamentos de cada uma das linhagens estão sumarizados na Tabela 2 e nas Figuras 1 e 2 . Esses resultados indicam que as quatro linhagens avaliadas, são capazes de degradar compostos fenólicos presentes nas águas residuárias da indústria metalúrgica.

Os níveis de degradação dos fenóis foram diferentes para cada um dos fungos avaliados, embora a maior degradação tenha ocorrido nos tempos de 24 e 48 horas de crescimento. Verificouse que a linhagem I- ${ }_{10}$ de Penicilium sp. foi a que apresentou os melhores resultados, conseguindo degradar $478 \mathrm{mg}$ do ácido gálico em 48 horas. Esse mesmo fungo consumiu $846 \mathrm{mg}$ de glicose em 96 horas de crescimento, tendo, com isso, produzido os maiores índices de biomassa microbiana.

\section{Tabela 2 - Níveis de fenóis, glicose e biomassa fúngica obtida em meio líquido.}

\begin{tabular}{|c|c|c|c|c|c|c|c|}
\hline \multirow{2}{*}{ Fungo } & \multicolumn{3}{|c|}{ Glicose } & \multicolumn{3}{|c|}{ Fenol } & \multirow{2}{*}{ Biomassa } \\
\hline & $24^{*}$ & 48 & 96 & 24 & 48 & 96 & \\
\hline $\mathrm{I}_{4}$ & $644 \pm 12 a$ & $421 \pm 56 b^{\#}$ & $211 \pm 45 d$ & $823 \pm 23 a$ & $734 \pm 15 a$ & $703 \pm 22 a$ & + \\
\hline $1-{ }_{6}^{4}$ & $431 \pm 10 b$ & $306 \pm 89 c$ & ND & $754 \pm 18 a$ & $692 \pm 21 a$ & $645 \pm 16 b$ & ++ \\
\hline $\mathrm{I}-{ }_{10}$ & $456 \pm 11 b$ & $267 \pm 78 d$ & $154 \pm 23 e$ & $817 \pm 20 a$ & $522 \pm 15 c$ & $518 \pm 15 c$ & +++ \\
\hline $\mid--_{13}$ & $676 \pm 15 a$ & $345 \pm 58 c$ & $178 \pm 35 e$ & $956 \pm 23 a$ & $665 \pm 19 b$ & $556 \pm 12 c$ & ++ \\
\hline
\end{tabular}

Médias seguidas da mesma letra, para os distintos testes, não diferem entre si pelo Teste de Tukey ao nível de $5 \%$ de probabilidade.

+: crescimento pequeno $(122 \mathrm{mg})$ / ++: crescimento médio $(265 \mathrm{mg}) /+++$ : crescimento grande (465mg). ND - Não detectado. * Tempo de observação em horas / "Valores obtidos em mg. L $^{-1}$ 
Figura 1 - Curva de consumo da glicose no processo.

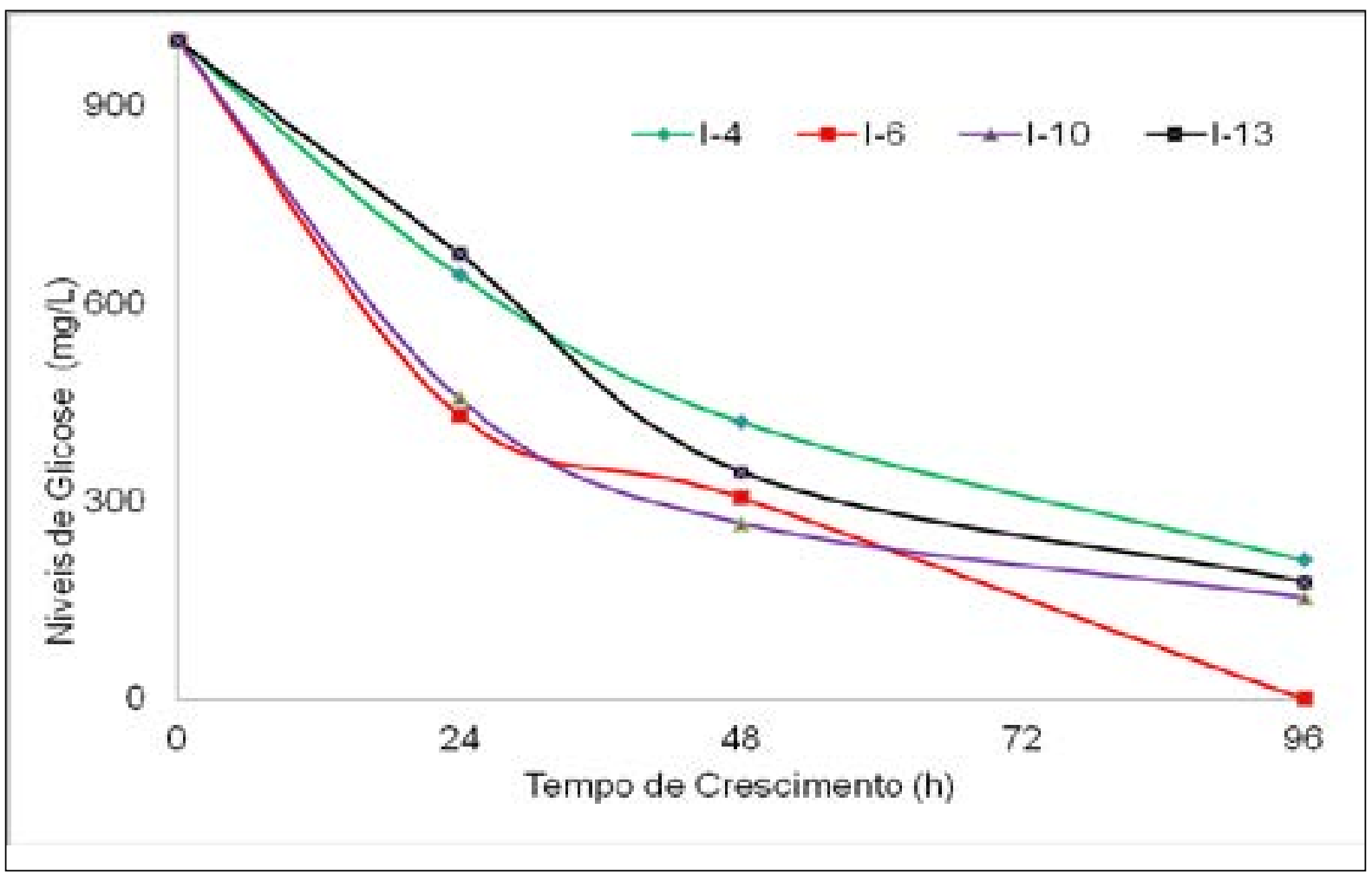

O mesmo comportamento foi verificado com o consumo de glicose, no qual não foram verificadas diferenças entre os fungos avaliados, porém foi observado que a linhagem I- ${ }_{6}$ de Cladosporium sp foi a que mais consumiu glicose, tendo consumido $100 \%$ da glicose fornecida e uma produção de biomassa média.

\section{Figura 2 - Curva de degradação do ácido gálico.}

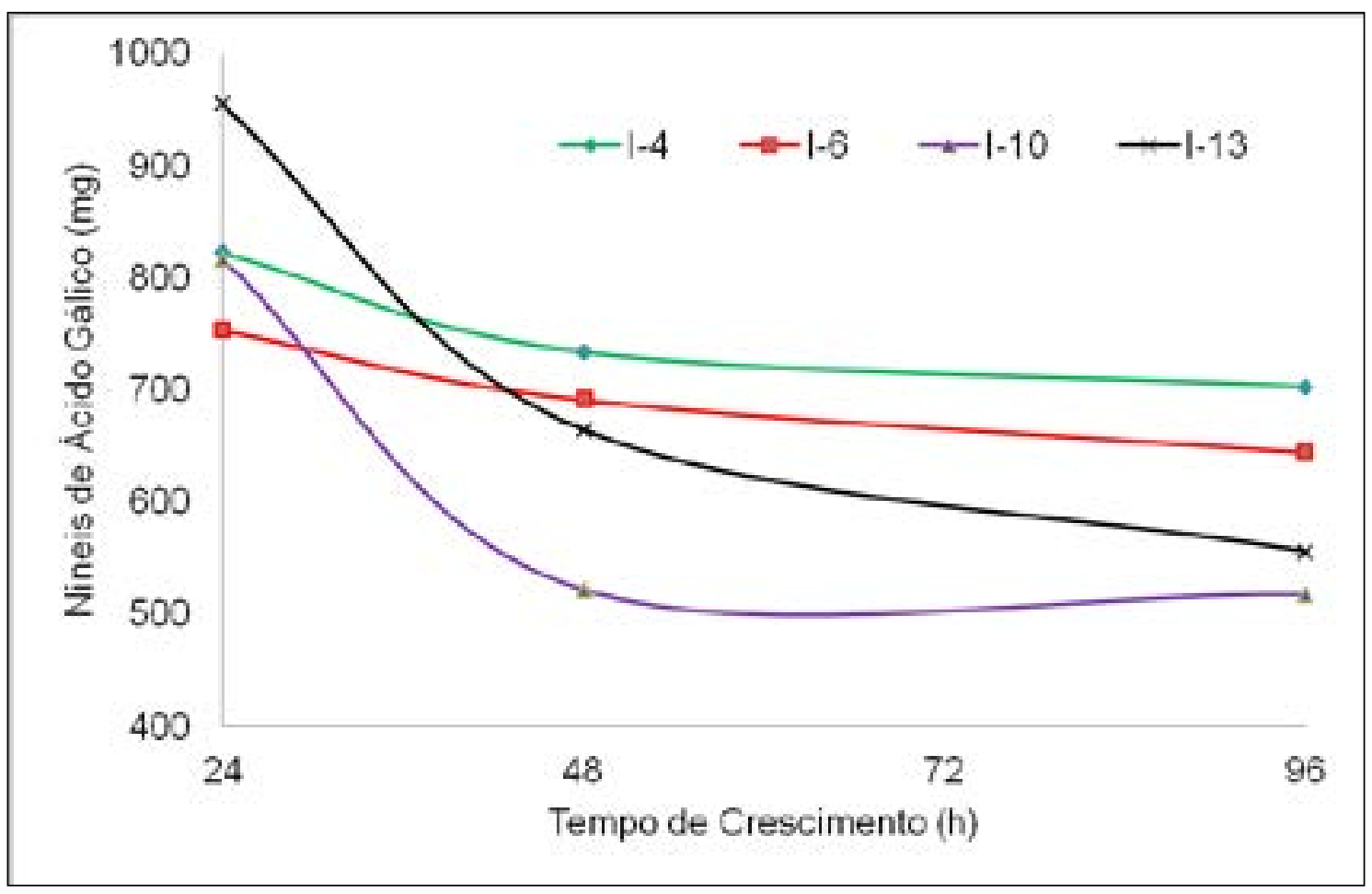


Dentre as linhagens fúngicas testadas, foi observado que muitas pertencem ao grupo de microrganismos com pigmentação escura. Devido ao complexo melanínico em suas paredes celulares, estes são chamados de dematiáceos ou fungos negros, os quais comumente apresentam melanina formada pelo polímero 1,8-dihidroxinaftaleno (DNH), produzido no citoplasma e excretado na parede celular (POLAK, 1990). Existem também outros precursores como catecolamina, catecol, tirosina, g-glutaminilhidroxibenzeno (GHB).

A síntese das melaninas fúngicas e outros pigmentos estão associados à oxidação de compostos fenólicos pelas fenoloxidases (GRIFFITH, 1994), justificando os resultados associados aos fungos filamentosos escuros. A melanina também está associada aos mecanismos de resistência dos fungos escuros sob condições ambientais adversas, o que justifica o gênero Cladosporium (dematiáceo) como o mais encontrado no efluente da indústria metalúrgica.

Alguns dos gêneros selecionados mostraram-se efetivos na degradação do pentaclorofenol. No trabalho realizado por Seigle-Murandi et al., (1995), Phoma glomerata degradou aproximadamente 30\% do organoclorado (100 mg. $\mathrm{L}^{-1}$ ). Minoura e Okazaki (1968) citaram a formação de halo em meio de ácido gálico ou tânico por Cladosporium cladosporioides e C. herbarum; Rösch and Liese (1971) demonstraram que os fungos Cladosporium cladosporioides, Penicillium sp e Aspergillus flavus desenvolvem-se em meio contendo taninos, os quais apresentam estruturas moleculares semelhantes às do ácido gálico. Donnison et al., (2000) revelaram a produção de fenoloxidases e peroxidases pelo fungo Cladosporium, isolado de solo alterado na Inglaterra.

Trabalhos sobre o isolamento de fungos filamentosos em ambientes estressantes encontraram uma diversidade de gêneros bastante semelhante à encontrada neste trabalho. Hofrichter et al., (1993) selecionaram os gêneros Penicillium, Mucor e Alternaria de solos contaminados por fenóis e benzeno provenientes do efluente industrial no leste da Alemanha.

Zhdanova et al., (2000) isolaram os gêneros Penicillium, Cladosporium, Fusarium, Aspergillus, Aureobasidium, Acremonium e Mucor, em locais com altos índices de radiação na Usina Nuclear de Chernobyl, alguns anos após um acidente nuclear. Assim, esses trabalhos confirmam que os gêneros encontrados nas águas residuárias da indústria metalúrgica, constituem um grupo de fungos filamentosos que definitivamente apresentam mecanismos de resistência a condições ambientais adversas e são capazes de degradar compostos fenólicos.

\section{Conclusão}

Foram isoladas e purificadas quatro linhagens de fungos filamentosos de águas residuárias da indústria metalúrgica. As espécies isoladas foram: Aspergillus flavus ( $\left.\mathrm{I}_{4}\right)$, Cladosporium sp (I- ${ }_{6}$ ), Penicilium sp $\left(\mathrm{I}_{10}\right)$ e Phoma sp ( $\left(\mathrm{I}_{13}\right)$. Os níveis de degradação dos compostos fenólicos, expressos em mg de equivalente de ácido gálico, foram diferentes para cada um dos fungos avaliados.

A maior degradação ocorreu nas primeiras 48 horas. A linhagem $\mathrm{I}_{10}$ de Penicilium sp foi a que apresentou os melhores resultados; conseguindo degradar $478 \mathrm{mg}$ em 48 horas, tendo com isso, produzido os maiores índices de biomassa microbiana. Todos os fungos selecionados demonstraram potencial importante para serem introduzidos em processos de biorremediação. 


\section{Conflitos de Interesse}

Os autores declaram que não existem conflitos de interesse no campo ético, editorial e financeiro sobre os dados deste trabalho.

\section{Referências}

ANDER, T.; MARZULO, L. Sugar oxidoreductase and veratril alcohol oxidase as related to lignindegradation. J. Biotechnol. v.53, p.115-131, 1997.

AOAC - Association of Official Analytical Chemists. Official methods of analysis of association of official analytical chemists. 11.ED. Washington: AOAC. 1970. 1075pp.

BENNET, J. W. Mycotechnology: the role of fungi in biotechnology.J. Biotechnol. v.66, p.101-107, 1998.

BRASIL - Ministério da Saúde. (2004). Portaria GM No 518 de 2004. disponível em www. http://www. uniagua.org.br/website/images/destaque/portaria518.Acesso em 14 de abril de 2015.

BUMPUS, J. A.; TIEN, M.; WRIGHT, D.; AUST, S. D. Oxidation of persistent environmental pollutants by a white rot fungi. Science. v.228, p.1434-1436, 1985.

COLL,P.M.; FERNÁNDEZ-ABALOS,J.M.; VILLANUEVA,J. R.; SANTAMARÍA, R.; PÉREZ, P. Purification and characterization of phenoloxidase (laccase) from lignindegrading basideomycete PM1 (CECT2971). Appl. Environ. Microbiol. v.59, n.8. p.2607-2613, 1993.

CUNHA, C. D. Avaliação da Biodegradação de Gasolina em Solo. Tese M. Sc. 197p. Universidade Federal do Rio de Janeiro, Escola de Química. Rio de Janeiro. Brasil. 1996.

DAVIDSON, R.W.; CAMPBELL, W.A.; BLAISDELL, D.J. Differentiation of wooddecaying fungi by their reactions on gallic or tannic acid medium. J. of Agric. Res. v.57, n.9, p.683-685, 1983.

DONNISON, L. M.; GRIFFITH, G. S.; HEDGER, J.; HOBBS, P. L.; BARDGETT, D. Management influences on soil microbial communities and their function in botanically diverse haymeadows of northern England and Wales. Soil Biol. Biochem. v.32, p.253263,2000 .

DURÁN, N.; ESPOSITO, E. Potential applications of oxidative enzymes and phenoloxidase-like compounds in wastewater and soil: a review. Appl. Catalysis B: Environmental. v.28, p.83-99, 2000. 
FOLIN, O.; CIOCALTEU, V. On tyrosine and triptophane determination in proteins. J. Biol. Chem. v.27, p.627-650, 1927.

FOLIN, O.; DENIS, W.Tyrosine in proteins as determined by a new colorimetric method. J. Biol. Chem. v.12, p.245-251, 1912.

GRIFFITH, G. W. Phenoloxidases. In: MARTINELLI, S. D.; KINGHORN, J. R. (Eds.).Aspergillus nidullans: 50 years on - progress in industrial microbiology. Amsterdam: Elsevier Science Publishers, 1994, p.763-788.

HOFRICHTER, M.; GÜNTHER, T.; FRITSCHE, W. Metabolism of phenol, chloroand nitrophenols by the Penicillium strain Bi 7/2 isolated from a contaminated soil. Biodegradation. v.3, p.415-421, 1993.

KHINDARIA, A.; GROVER, T. A.; AUST, S. D. Reductive dehalogenation of aliphatic halocarbons by lignin peroxidase of Phanerochaete chrysosporium. Environ. Sei. Technol. v.29, p.719-725, 1975.

KUNZ, A.; REGINATTO, V.; DURAN, N. Combined treatment of textile effluent using the sequence Phanerochaete chrysosporium - ozone. Chemosphere. v.44, p.281-287, 2001.

LEATHAM, G. F.; STAHMANN, M. A. Studies on the laccase of Lentinus edodes: specificity, localization and association with the development of fruiting bodies.J. General Microbiol.v.125, p.147-157, 1981.

MACRAE, R. HPLC in food analysis. New York: Academic Press. Chapter 2. 1988. p.678-689.

MINOURA, K.; OKAZAKI, G. Taxonomic Studies on cladosporia - physiological properties. J. Ferment. Technol. v.46, p.269-275, 1968.

NOBLES, M. K. Identification of cultures of wood-inhabiting hymenomycetes. Can.J. Bot.v.43, p.1097-1139, 1965.

PERALTA-ZAMORA, P.; GOMES, M. S.; ESPÓSITO, E.; ANTUNES, R.; REYES, J.; DURAN, N. Decolorization of pulp mill effluents with immobilized lignin and manganese peroxidase from Phanerochaete chrysosporidium. Environ.Sci. Technol. v.19, p.521-528, 1998.

POLAK, A. (1990). Melanin as a virulence factor in pathogenic fungi. Mycoses. v.33, n.5, p.215-224, 1990.

RODRIGUES, K. A. Uso de reatores biológicos com fungos para remoção de fenol de água residuária sintética, 2006. 127f. Tese - Universidade de São Paulo - USP - São Carlos São Paulo. Brasil, 2006. 
RÖSCH, R.; LIESE, W. Untersuchungen über die enzyme von Bläuepilsen Phenoloxidasen-Aktivität. Arch. Mikrobiol. v.76, p.212-218, 1971.

SANTOS, V. L.; LINARDI, V. R. (2004). Biodegradation of phenol by a filamentous fungi isolated from industrial effluents - identification and degradation potential.Process Biochem. v.39, p.1001-1006, 2004.

SEIGLE-MURANDI, F.; TOÉ, A.; BENOIT-GUYOD, J. L.; STEIMAN, R.; KADRI, M. (1995). Depletion of pentachorophenol by deuteromycetes isolated from soil. Chemosphere. v.31, n.2, p.2677-2686, 1995.

SEKHAR, K. C.; SUBRAMANIAN, S.; MODAK,J.M.; NATARAJAN, K. A. Renoval of metal íons on industrial biomass with reference to environmental control. Intern. J. Min. Proces. v.53, p.107-120, 1998.

THURSTON, C. F. The structure and function of fungal laccases. Microbiology. v.140, p.19-26, 1994.

TSIMIDOU, M.; PAPADOPOULOS, G.; BOSKOU, D. Phenolic compounds and stability of virgin olive oil - Part I. Food Chem. v.45, p.141-144, 1992.

VASSILEV, N.; BACA, M.T.; VASSILEVA, M. Plant lignocellulose and decomposition by fungy: from nature to industrial use. Mycologist. v.8, p.113-114, 1994.

WATERMAN, P. G.; MOLE, S. Analisys of phenolic plant metabolites. Blackwell Cientific Publications. Oxford. 1994, p.95-132.

ZHDANOVA, N. N.; ZAKHARCHENKO, V. A.; VEMBER, V. V. Fungi from Chernobyl: mycobiota of the inner regions of the containment structures of the damaged nuclear reactor. Mycol. Res. v.104, n.12, p.1421-1426, 2000. 